\title{
Lansoprazole reduced recurrence of ulcer complications in long term use of low dose aspirin
}

\author{
Lai KC, Lam SK, Chu KM, et al. Lansoprazole for the prevention of recurrences of ulcer complications from long-term \\ low-dose aspirin use. $N$ Engl J Med 2002;346:2033-8.
}

QUESTION: In patients receiving continuous treatment with low dose aspirin, is Helicobacter pylori eradication plus lansoprazole more effective than $H$ pylori eradication alone for preventing the recurrence of ulcer complications?

\section{Design}

Randomised \{allocation concealed*\}†, blinded (clinicians, patients, outcome assessors, monitoring committee, and data analysts),* placebo controlled trial with a median follow up of 12 months.

\section{Setting}

A university hospital in Hong Kong, China.

\section{Patients}

123 patients who were $18-80$ years of age (mean age $70 \mathrm{y}, 72 \% \mathrm{men}$ ) and had ulcers (gastric, duodenal, or gastroduodenal), were receiving low dose aspirin for $>1$ month before developing ulcers, had a disease such as stroke or ischaemic heart disease that required long term continuous treatment with low dose aspirin, and had $H$ pylori infection that was objectively diagnosed. Exclusion criteria included oesophagitis; a history of gastric or duodenal surgery other than oversewing of a perforation; allergy to study drugs; $H$ pylori infection that could not be eradicated after 2 attempts with eradication therapies; and concomitant treatment with nonsteroidal anti-inflammatory drugs, corticosteroids, or anticoagulants. Follow up was $92 \%$.

\section{Intervention}

After healing of the ulcers and eradication of $H$ Pylori infection, 62 patients were allocated to aspirin (100 $\mathrm{mg} / \mathrm{d})$ plus lansoprazole $(30 \mathrm{mg} / \mathrm{d})$, and 61 patients were allocated to aspirin $(100 \mathrm{mg} / \mathrm{d})$ plus placebo, all taken once daily for 12 months.

\section{Main outcome measures}

Recurrence of ulcer complications (bleeding, perforation, or obstruction).

\section{Main results}

Analysis was by intention to treat. Fewer patients in the lansoprazole group than in the placebo group had a recurrence of ulcer complications (table).

\section{Conclusion}

In patients receiving continuous treatment with low dose aspirin, Helicobacter pylori eradication plus lansoprazole was more effective than $H$ pylori eradication alone for preventing the recurrence of ulcer complications.

*See glossary.

†Information provided by author.

Source of funding: Peptic Ulcer Research Fund of the University of Hong Kong.

For correspondence: Dr K C Lai, Queen Mary Hospital, Hong Kong, China. kclai@hku.hk

Abstract and commentary also published in ACP Journal Club

\begin{tabular}{|c|c|c|c|c|}
\hline Outcome & Lansoprazole & Placebo & RRR (95\% Cl) & NNT (Cl) \\
\hline $\begin{array}{l}\text { Recurrence of ulcer } \\
\text { complications }\end{array}$ & $1.6 \%$ & $14.8 \%$ & $89 \%$ (37 to 98 ) & 8 (5 to 24$)$ \\
\hline
\end{tabular}

$\ddagger$ Abbreviations defined in glossary; RRR, NNT, and Cl calculated from data in article.

\section{COMMENTARY}

Even low doses of aspirin can cause serious ulcer complications. H pylori infection, which is a risk factor for aspirin associated ulcers, ${ }^{1}$ is more prevalent in Hong Kong (where the study by Lai $e t$ al was done) than in North America. Lai et al showed that eradication of $H$ pylor $i$ infection alone was inadequate for preventing recurrence of ulcer complications in Chinese patients who were restarted on low dose aspirin after ulcer healing. The combination of $H$ pylori eradication and subsequent maintenance with lansoprazole was substantially superior to $H$ pylori eradication alone in preventing ulcer complications within 1 year. We do not know the "natural" rate of recurrent ulcer complications without either of these interventions because the inclusion of a control group in which patients were not offered treatment for $H$ pylor $i$ infection would have been unethical.

A recent multinational study (currently only available in abstract form) found a point prevalence of endoscopic ulcers of $11 \%$ in patients who were receiving aspirin, 75-325 mg/day, but not nonsteroidal anti-inflammatory drugs, proton pump inhibitors, or $\mathrm{H}_{2}$ antagonists. ${ }^{1}$ Advancing age and $H$ pylori infection were risk factors for ulcers while dyspepsia was a negative predictor. Therefore, some patients receiving low dose aspirin (particularly the elderly and those who are asymptomatic) will have ulcers and will be at risk for complications. This does not mean that they all require long term treatment with proton pump inhibitors. However, those who have an ulcer complication should be tested for $H$ pylori infection, which should be treated if present. For such patients who are resuming low dose aspirin because of a medical necessity, long term proton pump inhibitor co-therapy after documented ulcer healing and $H$ pylori eradication is recommended.

Colin W Howden, MD Northwestern University Feinberg School of Medicine Chicago, Illinois, USA

1 Yeomans ND, Hawkey C, Lanas A, et al. Prevalence of gastric and duodenal ulcers during "low dose" aspirin. Gastroenterology 2002;122:A-87. 